\title{
The Functional and Economic Outcome of Lumber Discectomy: A Comparative Study of Fenestration Discectomy Versus Hemilaminectomy and Discectomy
}

\section{Ali A Alwan Al-Tamimi*}

Faculty of Medical Sciences, School of Medicine, University of Sulaimaniyah, Kurdistan, Iraq

"Corresponding author: Al-Tamimi AAA, Faculty of Medical Sciences, School of Medicine, University of Sulaimaniyah, Kurdistan, Iraq, Tel: 009647701448115; E-mail: alialwan2003@yahoo.com

Rec Date: May 16, 2017; Acc Date: July 22, 2017; Pub date: July 26, 2017

Copyright: () 2017 Al-Tamimi AAA. This is an open-access article distributed under the terms of the Creative Commons Attribution License, which permits unrestricted use, distribution, and reproduction in any medium, provided the original author and source are credited.

\begin{abstract}
Background: Lumber disc prolapse accounts for only $5 \%$ of all low back pain problems but is the most common cause of radiating nerve root pain which called sciatica. In the 20th century, techniques were developed to remove the herniated disc with minimal invasiveness, with these minimally invasive techniques; authors demonstrated decreased soft tissue manipulation, operative time, blood loss, and hospital stay, allowing early recovery.

Patients and methods: This is a prospective study carried in Sulaimaniyah Teaching hospital for 111 patients (72 male and 39 female) complained from lumber disc prolapse from May 2010 till May 2015. Two different surgical discectomy procedures were done to these patients as follows:

1. Fenestration discectomy was performed to 53 patients through $2-5 \mathrm{~cm}$ skin incision.

2. Hemilaminectomy and discectomy had done to 58 patients through skin incision $4-7 \mathrm{~cm}$.

3. The patients were evaluated preoperatively and 6 months postoperatively by PROLO score.
\end{abstract}

Results: 111 patients (72 male and 39 females with ratio 1.8:1) underwent surgical discectomy. The mean age of the patient was $36.2+6.2$ years.

Fenestration discectomy group: 53 patients $(47.7 \%)$ underwent fenestration discectomy. The operation time was ranging from $48-92 \mathrm{~min}$ with mean operative duration $69.13 \pm 8.96 \mathrm{~min}$. The mean hospital stay was $1.31 \pm$ 0.73 days ranging from 16 hours to 3 days. According to PROLO score, fair results were reported in four $(7 \%)$ patients while good result obtained in 12 patients $(23 \%)$ and 37 patients $(70 \%)$ showed excellent result. No patient expressed poor result.

Hemilaminectomy and discectomy group: 58 patients $(52.3 \%)$ underwent hemilaminectomy and discectomy. The operation time was ranging from 56-103 min with mean operative time $78.66 \pm 10.31 \mathrm{~min}$. The mean hospital stay was $2.46 \pm 1.42$ days ranging from 1 day to 10 days. According to PROLO score, 9 patients $(16 \%)$ obtained fair results while reliable results obtained in 15 patients (26\%) and excellent results founded in 34 patients (58\%). No patient showed poor results.

Discussion: Duration of the operation and hospital stay were significantly shorter in fenestration discectomy group than hemilaminectomy and discectomy one ( $p$-value less than 0.001). Through PROLO score both procedures showed significant improvement postoperatively in both economic and functional assessments. Most of our patients gain excellent results according to PROLO score in both surgical procedures. In this series $92 \%$ of patients treated with fenestration discectomy improved postoperatively with good or excellent score, while $85 \%$ of the patients treated with hemilaminectomy have that improvement.

Conclusion: Both fenestration discectomy and hemilaminectomy with discectomy showed the same final postoperative outcome but the fenestration discectomy is superior since the operation duration, hospital stay is less and overall improvement is relatively better.

Keywords: Lumber disc; Sciatica; Hemilaminectomy; Discectomy

\section{Introduction}

Lumber disc prolapse accounts for only $5 \%$ of all low back pain problems. It may irritate the dural covering of the adjacent nerve root causing pain in the buttock, posterior thigh and calf, which called sciatica [1] Although back pain is common from the second decade of life on, intervertebral disc herniation is most prominent in otherwise healthy people in the third and fourth decades of life [2]. Lumber discectomy is the most common operation performed in the United States for lumbar-related symptoms [3]. 
Page 2 of 8

Mixter and Barr [4] described the first surgical procedure to remove the herniated lumbar disc in 1934 through a laminectomy and durotomy, with later enhancement by Semmes, who described approaching the herniated disc through hemilaminectomy and retraction of the dural sac. This became popularized as the "classical discectomy technique" [4]. During the latter half of the 20th century, more techniques were developed to remove the herniated disc with minimal invasiveness [5]. With these minimally invasive techniques, authors demonstrated decreased soft tissue manipulation, operative time, blood loss, and hospital stay, allowing early recovery [5].

\section{Patients and Methods}

This is a prospective study carried in Sulaimaniyah Teaching Hospital for 111 patients (72 male and 39 female) complained from lumber disc prolapse from May 2010 till May 2015.

The patient examined thoroughly concentrating on neurological status to exclude any sensory or motor deficit and orthopedically to elicit any abnormal gait, sciatica scoliosis and or any sign of root irritation. Tension tests were done in form of straight leg raising test (SLRT), cross leg raising test and Laseque test.

All patients underwent plain radiographic examination with anteroposterior (AP) view to exclude sacralization and lumberlization of the spine and lateral view in flexion and extension to exclude any instability. All the patients should have recent MRI within the last three months.

All operations done under general anesthesia, intraoperative antibiotic in a form of 1-gram ceftriaxone is given during the induction of the anesthesia. Knee-Chest position was performed to all patients; the level of the prolapsed disc was determined prior to skin incision by the assistance of C-arm fluoroscopy.

1. Fenestration discectomy was performed to 53 patients through 2-5 cm skin incision done according to the intervertebral level.

2. Hemilaminectomy and discectomy had done to 58 patients through skin incision 4-7 cm according to the affected levels.

The patients followed and examined every month for the first 6 months and every 3 months for 2 years. Patients with intraoperative or postoperative complications were treated and followed postoperatively according to each case.

At the end of the follow up PROLO scale [6] (Economical and Functional scale) was used to evaluate the outcome of the surgery (Table 1).

\begin{tabular}{|l|l|}
\hline Economic ability & Score \\
\hline Complete invalidity & 1 \\
\hline $\begin{array}{l}\text { No gainful occupation, including ability to do housework, or continue } \\
\text { retirement activities }\end{array}$ & 2 \\
\hline $\begin{array}{l}\text { Able to work, but not at previous occupation; able to perform } \\
\text { housework and retirement activities }\end{array}$ & 3 \\
\hline Working at previous occupation part-time or limited status & 4 \\
\hline
\end{tabular}

\begin{tabular}{|l|l|}
\hline Able to work at previous occupation with no restrictions of any kind & 5 \\
\hline Functional ability & Score \\
\hline Total incapacity (postoperative: worse than prior to operation) & 1 \\
\hline $\begin{array}{l}\text { Difficulty in walking, needing a cane or crutch or persistent moderate } \\
\text { motor weakness (able to perform tasks of daily living }\end{array}$ & 2 \\
\hline $\begin{array}{l}\text { Slight difficulty in walking, but without help; slight motor weakness, } \\
\text { moderate pain, persistent paraesthesia }\end{array}$ & 3 \\
\hline $\begin{array}{l}\text { No difficulty in walking, no motor weakness, no pain but persistent } \\
\text { paraesthesia. }\end{array}$ & 4 \\
\hline $\begin{array}{l}\text { No difficulty in walking, no motor weakness, no pain, no paraesthesia, } \\
\text { able to perform sports activities }\end{array}$ & 5 \\
\hline
\end{tabular}

Table 1: Economic ability and functional ability.

Total score will be 2-10, scoring method and Interpretation is that, the lower the score is the more severe the deficits. Excellent: 9-10, Good: 7-8, Fair: 5-6, Poor: 2-4 [6].

\section{Inclusion criteria}

- One level or two-level disc prolapse.

- Age between 18-45 years.

\section{Exclusion criteria}

- Multiple level disc prolapses (more than 2 levels).

- Unstable spine

- Age above 45 years.

- Cauda equine syndrome.

- Previous spine or disc surgery.

- History of spine pathology like TB or Malignancy and major trauma that might cause fracture spine.

\section{Statistical analysis}

After data collection and prior to data entry and analysis, the questions of study were coded. Data entry performed via using an excel spreadsheet then the statistical analysis was performed by SPSS program, version 21 (IBM SPSS Statistical Package for the Social Sciences). The quantitative continuous variables were described by mean and SD (standard deviation). Chi-square tests were used to compare the categorical data between these two groups of patients (the two methods of surgery) in respect to different variables. $p$-values of 0.05 were used as a cut off point for significance of statistical tests.

\section{Results}

111 patients (72 male and 39 females with ratio 1.8:1) underwent surgical discectomy. The mean age of the patient was $36.2+6.2$ years; ranged between $18-45$ years. $60 \%$ of our patients were aged between 31-40 years (Figure 1). 
Citation: Al-Tamimi AAA (2017) The Functional and Economic Outcome of Lumber Discectomy: A Comparative Study of Fenestration Discectomy Versus Hemilaminectomy and Discectomy . J Spine 6: 379. doi:10.4172/2165-7939.1000379

Page 3 of 8

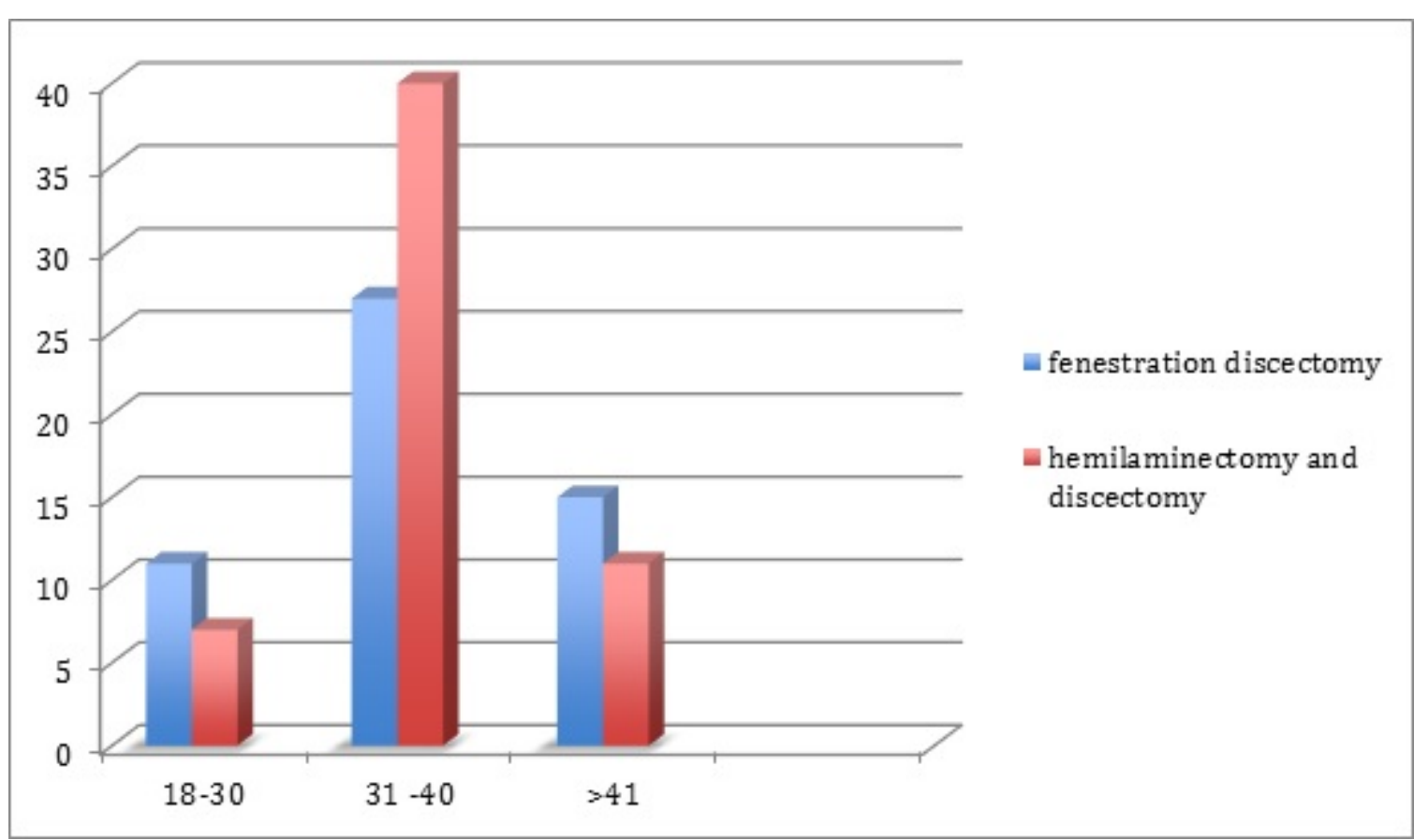

Figure 1: Age distribution among the studied cases.

The back pain was radiated to the left lower limb in 63 patients (56.7\%) and to the right lower limb in 40 patients (36\%) and to both limb in 8 patients (7.2\%). Sciatic scoliosis was complained by 17 patients $(15.3 \%)$. All patients $(100 \%)$ presented with sciatica. Numbness was founded in 59 patients $(53.2 \%)$. SLRT was positive in all patients at angle $30-60^{\circ}$, cross leg raising test was positive in 42 patients $(37.8 \%)$, sensory deficit was found in 47 patients $(42.3 \%)$, motor deficit was found in 67 patients $(60.4 \%)$ and deep ankle reflex was altered in 23 patients (20.7\%) (Table 2).

\begin{tabular}{|c|c|c|c|c|c|}
\hline \multirow[t]{2}{*}{ Symptoms and signs } & \multicolumn{2}{|c|}{ Fenestration discectomy } & \multicolumn{2}{|c|}{ Laminectomy and discectomy } & \multirow[b]{2}{*}{$P$ value } \\
\hline & No. & $\%$ & No. & $\%$ & \\
\hline Sciatic scoliosis & 7 & 13 & 10 & 17 & 0.91 \\
\hline SLRT & 53 & 100 & 58 & 100 & 0.86 \\
\hline Cross leg raising test & 19 & 36 & 23 & 40 & 0.56 \\
\hline Sensory deficit & 25 & 47 & 22 & 38 & 0.73 \\
\hline Motor deficit & 31 & 58 & 36 & 62 & 0.44 \\
\hline Diminished ankle reflex & 16 & 30 & 7 & 12 & 0.18 \\
\hline
\end{tabular}

Table 2: The detailed physical examination findings in both surgical groups.

The prolapsed disc was at L4-L5 level in 72 patients (64.9\%), while in 27 patients $(24.3 \%)$ the prolapse disc was at L5-S1 and in 12 patients (10.8\%) both levels L4-L5 and L5-S1 were affected. Lateral disc was found in 89 patients $(80.2 \%)$, central disc prolapse was found in 17 patients $(15.3 \%)$ and in five patients $(4.5 \%)$ the disc was prolapsed laterally in one level and centrally in the other level. Protruded disc was found in 20 patients (18\%), extruded disc was found in 83 patients $(74.8 \%)$ and sequestrated disc was found in 8 patients $(7.2 \%)$ (Table 3$)$.

\section{Fenestration discectomy group}

53 patients $(47.7 \%)$ underwent fenestration discectomy, 32 patients were male and 21 patients were female. The operation time was ranging from 48-92 min with mean operative duration $69.13 \pm 8.96$ min. The mean hospital stay was $1.31 \pm 0.73$ days ranging from 16 hours to 3 days (Table 4 ). 
Citation: Al-Tamimi AAA (2017) The Functional and Economic Outcome of Lumber Discectomy: A Comparative Study of Fenestration Discectomy Versus Hemilaminectomy and Discectomy . J Spine 6: 379. doi:10.4172/2165-7939.1000379

Page 4 of 8

\begin{tabular}{|c|c|c|c|c|c|}
\hline \multirow[t]{2}{*}{ Disc level } & \multicolumn{2}{|c|}{ Fenestration discectomy } & \multicolumn{2}{|c|}{ Laminectomy and discectomy } & \multirow[b]{2}{*}{$P$ value } \\
\hline & No. & $\%$ & No. & $\%$ & \\
\hline L4 - L5 & 32 & 60 & 40 & 69 & 0.12 \\
\hline L5 - S1 & 16 & 30 & 11 & 19 & 0.35 \\
\hline Both & 5 & 10 & 7 & 12 & 0.93 \\
\hline Total & 53 & 100 & 58 & 100 & \\
\hline \multirow[t]{2}{*}{ Direction of prolapse } & \multicolumn{2}{|c|}{ Fenestration discectomy } & \multicolumn{2}{|c|}{ Laminectomy and discectomy } & \\
\hline & No. & $\%$ & No. & $\%$ & $P$ value \\
\hline Para central & 43 & 81 & 46 & 79 & 0.55 \\
\hline Central & 7 & 13 & 10 & 17 & 0.21 \\
\hline Both & 3 & 6 & 2 & 4 & 0.36 \\
\hline Total & 53 & 100 & 58 & 100 & \\
\hline \multirow[t]{2}{*}{ Type of prolapse } & \multicolumn{2}{|c|}{ Fenestration discectomy } & \multicolumn{2}{|c|}{ Laminectomy and discectomy } & \\
\hline & No. & $\%$ & No. & $\%$ & $P$ value \\
\hline Protrusion & 12 & 23 & 8 & 14 & 0.88 \\
\hline Extrusion & 36 & 68 & 47 & 81 & 0.67 \\
\hline Sequestration & 5 & 9 & 3 & 5 & 0.95 \\
\hline Total & 53 & 100 & 58 & 100 & \\
\hline
\end{tabular}

Table 3: The characteristics of disc prolapse in both surgical groups.

\section{Hemilaminectomy and discectomy group}

58 patients $(52.3 \%)$ underwent hemilaminectomy and discectomy, 40 patients were male and 18 were female. The operation time was ranging from $56-103$ min with mean operative time $78.66 \pm 10.31$ min. The mean hospital stay was $2.46 \pm 1.42$ days ranging from 1 day to 10 days (Table 4 ).

\begin{tabular}{|l|l|l|l|l|l|}
\hline \multirow{2}{*}{ Operation duration and hospital stay } & \multicolumn{2}{|l|}{ Fenestration discectomy } & \multicolumn{3}{l|}{ Hemilaminectomy and discectomy } \\
\cline { 2 - 6 } & Mean & SD & Mean & SD & P value \\
\hline Operation duration (Minutes) & 69.13 & 8.96 & 78.66 & 10.31 & $<0.001$ \\
\hline Hospital stay (Days) & 1.31 & 0.73 & 2.46 & 1.42 & $<0.001$ \\
\hline
\end{tabular}

Table 4: The mean operative time and hospital stay of fenestration discectomy and hemilaminectomy and discectomy groups.

\begin{tabular}{|l|l|l|l|l|}
\hline \multirow{2}{*}{ Complications } & \multicolumn{2}{|l|}{ Fenestration discectomy } & \multicolumn{2}{l|}{ Laminectomy and discectomy } \\
\cline { 2 - 5 } & No. & $\%$ & No. & \% \\
\hline Dural tear & 0 & 0 & 1 & 2 \\
\hline Nerve root injury & 1 & 2 & 1 & 0.34 \\
\hline Superficial infection & 3 & 6 & 5 & 2 \\
\hline Total & 4 & 8 & 7 & 8.95 \\
\hline
\end{tabular}

Table 5: The complications of both surgical groups. 
Citation: Al-Tamimi AAA (2017) The Functional and Economic Outcome of Lumber Discectomy: A Comparative Study of Fenestration Discectomy Versus Hemilaminectomy and Discectomy . J Spine 6: 379. doi:10.4172/2165-7939.1000379

Page 5 of 8

The operative time and hospital stay in fenestration discectomy is significantly shorter than that of hemilaminectomy and discectomy since the $\mathrm{p}$-value less than 0.001 .

Out of 53 patients treated by fenestration discectomy only 4 patients (8\%) suffered from distinct types of intra and/or postoperative complications; while 7 patients (12\%) out of 58 suffered from those complications in those patients whom operated on by hemilaminectomy and discectomy (Table 5).

There are no significant differences between the two modalities regarding the several types of reported complications since the p-value more than 0.05 .
All patients were subjected to economical and functional score (PROLO) preoperatively and 6 months postoperatively.

- In fenestration group four (7\%) patients showed fair results while good result obtained in 12 patients (23\%) and 37 patients $(70 \%)$ showed excellent result. No patient expressed poor result.

- In hemilaminectomy and discectomy group nine patients (16\%) obtained fair results while superior results obtained in 15 patients (26\%) and excellent results founded in 34 patients (58\%). No patient showed poor results (Tables 6 and 7, Figure 2).

\begin{tabular}{|c|c|c|c|c|}
\hline \multicolumn{2}{|c|}{ PROLO Economic and Functional assessment scale } & \multicolumn{2}{|l|}{ Mode of surgery } & \multirow{3}{*}{$\begin{array}{l}\mathbf{P} \text { value } \\
0.92\end{array}$} \\
\hline & & Fenestration discectomy & Hemilaminectomy and discectomy & \\
\hline \multirow[t]{3}{*}{ Economic Pre-op } & E1 & 16 & 19 & \\
\hline & E2 & 33 & 34 & \\
\hline & E3 & 4 & 5 & \\
\hline \multirow[t]{3}{*}{ Economic Post op } & E3 & 7 & 12 & \multirow[t]{3}{*}{0.27} \\
\hline & E4 & 8 & 13 & \\
\hline & E5 & 38 & 33 & \\
\hline \multirow[t]{3}{*}{ Functional Pre-op } & $\mathrm{F} 1$ & 20 & 15 & \multirow[t]{3}{*}{0.38} \\
\hline & $\mathrm{F} 2$ & 29 & 39 & \\
\hline & F3 & 4 & 4 & \\
\hline \multirow[t]{3}{*}{ Functional Post op } & F3 & 8 & 13 & \multirow[t]{3}{*}{0.31} \\
\hline & $\mathrm{F} 4$ & 10 & 15 & \\
\hline & F5 & 35 & 30 & \\
\hline
\end{tabular}

Table 6: Distribution of the patient according to economic and functional PROLO scale of both procedures.

\begin{tabular}{|l|l|l|l|}
\hline Final outcome & Fenestration discectomy & Hemilaminectomy and discectomy & P value \\
\hline Fair & 4 & 9 & 0.34 \\
\hline Good & 12 & 15 & \\
\hline Excellent & 37 & 34 & 58 \\
\hline Total & 53 & 58 & \\
\hline
\end{tabular}

Table 7: The final outcome of both fenestration and hemilaminectomy groups. 
Citation: Al-Tamimi AAA (2017) The Functional and Economic Outcome of Lumber Discectomy: A Comparative Study of Fenestration Discectomy Versus Hemilaminectomy and Discectomy . J Spine 6: 379. doi:10.4172/2165-7939.1000379

Page 6 of 8

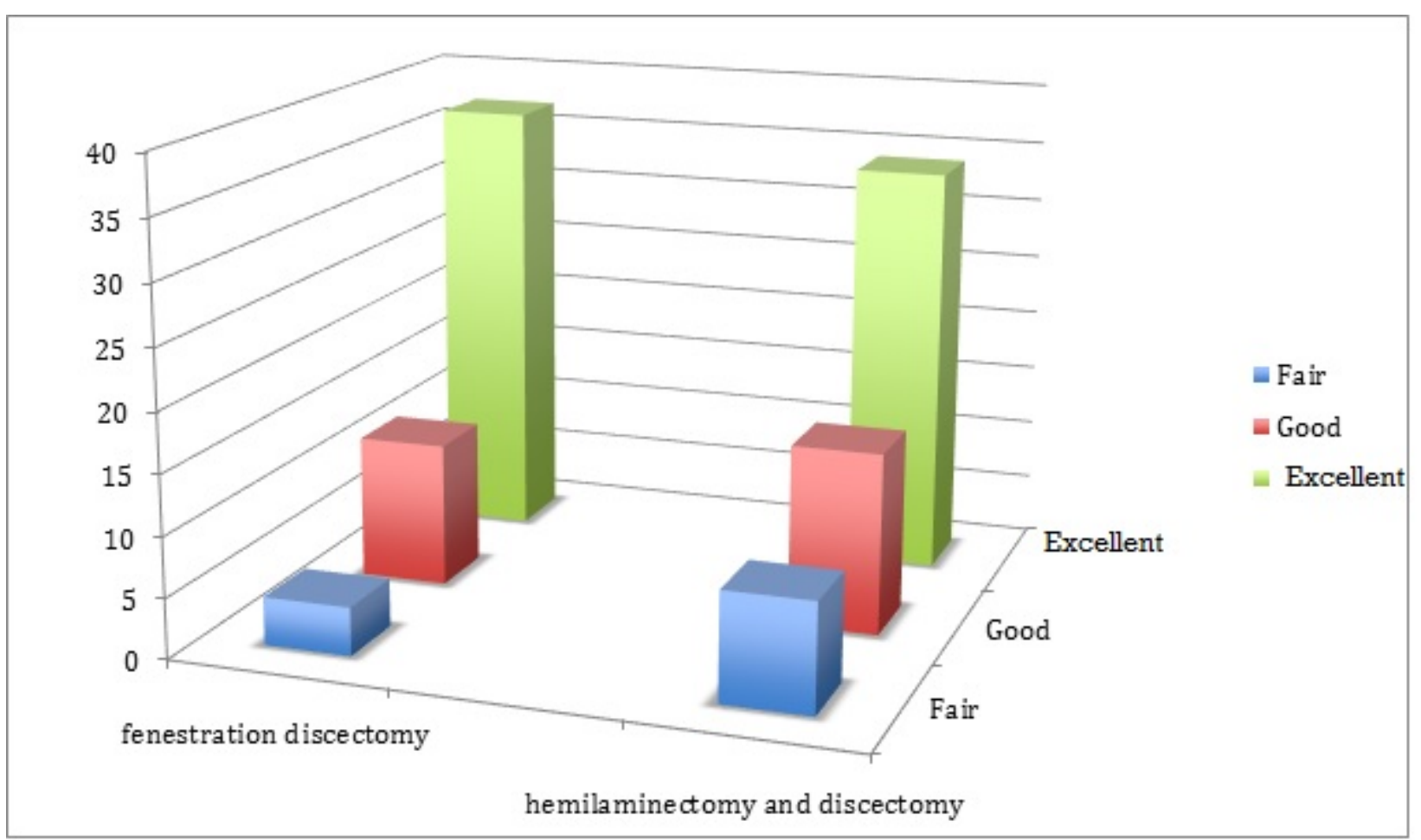

Figure 2: The final outcome of both fenestration and hemilaminectomy groups.

From the above data, we can notice that despite the differences in the values of the outcome but there were no significant differences between the two procedures in term economic, functional and in the overall end results ( $\mathrm{p}$-value more than 0.05 ).

\begin{tabular}{|l|l|l|l|}
\hline \multirow{2}{*}{ Type of surgery } & \multicolumn{2}{|l|}{ Mean PROLO economic Score \pm SD } & P Value* \\
\cline { 2 - 4 } & Economic Pre-op Scale & Economic Post op Scale \\
\hline Fenestration discectomy & $1.77 \pm 0.57$ & $4.58 \pm 0.71$ & $<0.001$ \\
\hline Hemilaminectomy and discectomy & $1.76 \pm 0.60$ & $4.36 \pm 0.80$ & $<0.001$ \\
\hline- * Performed by paired t test & & & \\
\hline
\end{tabular}

Table 8: The mean score of pre and postoperative economic score in both procedures.

\begin{tabular}{|l|l|l|l|}
\hline \multirow{2}{*}{ Type of surgery } & Mean Score \pm SD & P Value * \\
\cline { 2 - 4 } & Functional Pre op Scale & Functional Post op Scale \\
\hline Fenestration discectomy & $1.70 \pm 0.60$ & $4.51 \pm 0.74$ & $<0.001$ \\
\hline Hemilaminectomy and discectomy & $1.81 \pm 0.54$ & $4.29 \pm 0.81$ & $<0.001$ \\
\hline Performed by paired t test & \multicolumn{2}{|l}{} \\
\hline
\end{tabular}

Table 9: The mean score of pre and postoperative functional score in both procedures.

There were significant differences between the pre-and postoperative results regarding the economic and functional assessment in both fenestration discectomy and hemilaminectomy and discectomy procedures ( $\mathrm{p}$-value $<0.001$ ) (Tables 8 and 9 ).

\section{Discussion}

Lumber disc prolapse consider as one of most common causes of spine surgery. Many surgical procedures were described for discectomy like full or total laminectomy with discectomy, hemilaminectomy and 
discectomy, fenestration discectomy, microscopic discectomy and endoscopic discectomy.

In this study, we compare between two modalities of discectomy, which are fenestration discectomy and classical hemilaminectomy and discectomy. Since most of lumber disc prolapse affected young adults in their productive life, so we need to evaluate which procedure provide quick return to normal life.

\section{Age and sex}

In our study $60 \%$ of our patients aged between $31-40$ years with males affected as twice as the females. This is a known fact in all literatures in which they showed that lumber disc prolapse is more common young active healthy people in their third and fourth decades of life, this is because the prolapse happen due to heavy exertion, repetitive bending, twisting, or heavy lifting; things that usually done by young adult male $[2,7]$.

\section{Symptoms and signs}

In this study, the back pain radiated (sciatica) more to left lower limb $56.7 \%$ and only $7.2 \%$ of patients, the pain was radiated to both limbs. There was no any difference in the outcome and the complication that related to the side of pain radiation.

SLRT was positive in all cases while cross leg raising test was positive in $37.8 \%$ of cases; this is comparable to study done by Ujwal et al. [8]. Sensory deficit was elicited in $42.3 \%$ of the patients; motor deficit in $60.4 \%$ and diminished ankle reflex was founded in $20.7 \%$. Sciatic scoliosis was found in $15.3 \%$ of the patients in this study.

\section{Prolapsed disc properties}

Most of prolapsed disc was found at L4-L5 level (64\%) and only $12 \%$ of our patient suffered from L4-L5 and L5-S1 simultaneously. 75\% of the prolapsed discs was found extruded, while sequestrated discs were diagnosed in $7 \%$ of the patients. Most of patients were presented with pure lateral disc herniation (80\%). In this study; we found that, the level of the prolapsed discs, the location of the discs and the type of the disc prolapse play no role in the selection of the type of surgery, the complications and the outcome. Omidi-Kashani et al. [9] reported that the ultimate satisfaction rates at final follow-up visit are similar and comparable between the L4-5 and L5-S1 levels.

\section{Fenestration discectomy versus hemilaminectomy and discectomy}

Fenestration discectomy was performed to 53 patients (47.7\%) and discectomy through hemilaminectomy were done to 58 patients (52.3\%). We compare both procedures in the following points:

Duration of operation: In the fenestration group, the mean operative time was $69.13 \pm 8.96$ min which was significantly shorter than the hemilaminectomy group which was $78.66 \pm 10.31 \mathrm{~min}(\mathrm{p}-$ value $>0.001$ ), this is can be attributed to less soft tissue dissection, minimal bonny procedure with flavectomy and smaller incision which need less time for closure. Ujwal et al. [8] in their study reported 75 min as a mean operative time for fenestration discectomy. A study done by Adam et al. [10] showed significant shorter operative time with fenestration (mean time was $70 \mathrm{~min}$ ) than the time of laminectomy (mean time $105 \mathrm{~min}$ ).
Hospital stays: In this series, we noticed that the hospital stays in fenestration group (mean $1.31 \pm 0.73$ days) was significantly less than the hemilaminectomy group (mean $2.46 \pm 1.42$ days) with p-value less than 0.001 . The small incision, less muscle dissection will decrease the postoperative pain in which will decrease hospital stay. Harrington [11] stated that reduced postoperative pain in minimally invasive techniques would reduce hospital stay.

Operative and post-operative complications: From our data we can notice that, although the complications reported in the hemilaminectomy were more than those in fenestration group there were no significant differences between both procedures ( $p$-value $>0.05$ ). We recorded two root injuries one in each group, it is well known fact that root injury is represent $1 \%$ of all discectomy procedures, although Nancy Epstein [12] stated that the minimal invasive techniques carries more nerve root injuries than the classical one. Dural tear was reported in one patient of the hemilaminectomy group and not recorded in fenestration one this was happened accidently while retracting the Dura to separate a very adherent sequestrated disc. Superficial stitch infection recorded in 8 patients in both groups and treated conservatively by antibiotics without any effect on the overall result of surgery.

PROLO economic and functional scale assessment and outcome: In our series, we found that most of our patient in both groups are preoperatively economically scored E2 which is No gainful occupation, including ability to do housework, or continue retirement activities and functionally scored F2 which is Difficulty in walking, needing a cane or crutch or persistent moderate motor weakness (able to perform tasks of daily living). There were no statistical differences between the fenestration and hemilaminectomy groups preoperatively and postoperatively in both economical and functional scores ( $p$-value more than 0.05 ). Six months postoperatively, the score is significantly improved in both procedures economically and functionally ( $\mathrm{p}$-value less than 0.001). PROLO score assessed the patient economically and functionally and it describes more details than other score systems like Macnabs, although the end score of both systems are the same [8]. PROLO score when created in 1986, it was for evaluation of vertebral interbody fusion, this rating scale is easily applicable and can delineate pre- and postoperative conditions of patients on a semi quantitative basis [13]. Several researchers administered the original PROLO score as a main outcome or in association with other outcome measures, mostly in studies conducted on degenerative pathologies of the lumbar spine. Some authors used the PROLO by properly adapting items for the postoperative evaluation of function of other spinal districts, for example, the thoracic spine in case of fracture stabilization or discectomy or the cervical spine [6]. PROLO score system consist of two scores the first one is Economic (E), in which the patient evaluated according to the ability to return to his previous job in complete or part time, need modification of the job, need to change the entire job or should retired. The other score is the functional (F) which related to the degree of pain, motor and sensory deficit postoperatively.

In this series 38 patients out of $53(71.69 \%)$ in fenestration group and 33 patients out of 58 (56.89\%) in hemilaminectomy group were returned to their previous jobs within 6 months postoperatively. Our results in fenestration group were comparable with Ujjwal et al. [8] who stated that; according to PROLO economical scale, (72\%) of cases could work at their previous job without any recurrences while (12\%) were able to work at previous occupation but part time or limited status while $(16 \%)$ cases were able to work but had to abandon their previous occupation. In our study $15 \%$ of fenestration group and $22 \%$ 
Citation: Al-Tamimi AAA (2017) The Functional and Economic Outcome of Lumber Discectomy: A Comparative Study of Fenestration Discectomy Versus Hemilaminectomy and Discectomy . J Spine 6: 379. doi:10.4172/2165-7939.1000379

Page 8 of 8

of hemilaminectomy group was able to return back to their previous job but in part time or with limited effort, while the rest of the patients were able to work but they changed their previous jobs. We also noticed that there were a considerable number of our patients even if their final functional score were F3 or F4, they scored E5 in economic score. We believed that many of our patients (especially the governmental employers) were not able to change their jobs style easily, so they were enforced to continue with their previous jobs even with remnant postoperative symptoms.

We reported 45 patients (85\%) of fenestration group and 45 patients (77.5\%) in hemilaminectomy group as free of pain (F4 and F5) at the end of 6 months. This is also comparable with Ujwal et al. [8] study in which they recorded that $88 \%$ of their patients were relieved of pain at the end of 6 months.

Most of our patients gain excellent results according to PROLO score in both surgical procedures. Excellent results were more in fenestration group (37 patients) than that in hemilaminectomy group (34 patients). There was no significant statistical difference between the two procedures ( $\mathrm{P}$ vale more than 0.05 ). Overall most of our patients improve in both economic and functional scores in both procedures, which mean that final satisfactory outcome, were gained in both procedures.

In this series $92 \%$ of patients treated with fenestration discectomy improved postoperatively to good or excellent, while $85 \%$ of the patients treated with hemilaminectomy and discectomy group were improved to good or excellent postoperatively. This is comparable to study of Dennis Antony et al. [14] who recorded good improvement in $88 \%$ of the patients. Ujwal et al. [8] in their study reported good improvement in $84 \%$ of their cases.

Out of 111 patients, we had only 13 patients with fair outcome at the end of 6 months (4 patients in fenestration and 9 in hemilaminectomy groups); although the number of patients was much less in fenestration group, this difference was statistically not significant (p-value more than 0.05). Both Dennis [14] and Ujwal [8] drop excellent from their studies and they consider score below 5 as poor, 6-7 as fair and 8-10 as good.

\section{Conclusion}

From this study, we can conclude that although fenestration discectomy and discectomy through hemilaminectomy carries almost the same successful and satisfactory outcome, fenestration discectomy is superior in minimizing dissection, operation duration, postoperative pain and hospital stay. PROLO score is easy, dependable and predictable way to evaluate the economic and the functional outcome of the patients treated with lumber discectomy.

\section{References}

1. Solomon L, Warwick D, Nayagam S (2010) Apley's system of orthopaedics and fractures. (9th edn). Hodder Arnold Publications, London. pp: 478-481.

2. Canale ST, Beaty JH (1935) Campbell's operative orthopaedics, (12th edn) International Edition. Elsevier-Mosby, Maryland, USA.

3. Weinstein JN, Lurie JD, Tosteson TD, Skinner JS, Hanscom B, et al. (2006) Surgical vs. non-operative treatment for lumbar disk herniation: The Spine Patient Outcomes Research Trial (SPORT) observational cohort. JAMA 296: 2451-2459.

4. Gotfryd A, Avanzi O (2009) A systematic review of randomised clinical trials using posterior discectomy to treat lumbar disc herniations. Int Orthop 33:11-17.

5. Evaniew N, Khan M, Drew B, Kwok D, Bhandari M, et al. (2014) Minimally invasive versus open surgery for cervical and lumbar discectomy: A systematic review and meta-analysis. CMAJ Open 2: E295-305.

6. Vantim C, Prosperi D, Boschi M (2013) The Prolo Scale: History, evolution and psychometric properties. J Orthp Traumatol 14: 235-245.

7. Koval KJ (2002) Orthopaedics knowledge update, Home Study Syllabus J Am Acad Orthop Surg. p. 632.

8. Wankhede GU, Umashankar MK, Reddy BSJ (2016) Functional outcome of lumbar discectomy by fenestration technique in Lumbar disc prolapsereturn to work and relief of pain. J Clin Diagn Res 10: RC0-RC13.

9. Omidi-Kashani F, Jarahi L, Jafarian M, Anjomrouz RM (2014) Impact of herniation level on surgical outcome of microlumbar discectomy. Austin J Orthopade \& Rheumatol 1:3.

10. Adam D, Hornea I, Burduşa G, Iftimie D, Moisescu C (2016) A retrospective comparison of laminectomy and unilateral fenestration with foraminotomy on outcome of patients with lumbar spinal stenosis. Romanian Neurosurgery 1: 6-14.

11. Harrington JF, French P (2008) Open versus minimally invasive lumbar microdiscectomy: Comparison of operative times, length of hospital stay, narcotic use and complications. Minim Invasive Neurosurg 51: 30-35.

12. Epstein NE (2016) More nerve root injuries occur with minimally invasive lumbar surgery, especially extreme lateral interbody fusion: A review. Surg Neurol Int 7: S83-S95.

13. Prolo DJ, Oklund SA, Butcher M (1986) Towards uniformity in evaluating results of lumbar spine operations. A paradigm applied to posterior lumbar interbody fusions. Spine 11: 601-606.

14. Antony D, Jose R (2016) Functional outcome of lumber fenestration discectomy in patients with intervertebral disc prolapse treated at a tertiary care Centre in south India. JEMDS 5: 6689-6693. 